\title{
Articulação entre Prova Brasil e avaliação institucional: percepções dos professores
}

\author{
Articulation between Prova Brasil and institutional evaluation: \\ teachers' perceptions
}

\author{
Carla Daniela Ramos da CRUZ 1 \\ Mônica Piccione Gomes RIOS 2
}

\begin{abstract}
Resumo
As escolas públicas municipais de Campinas (SP) possuem uma política pública de avaliação institucional, de caráter democrático e emancipatório; concomitante à Prova Brasil, que dá origem ao Índice de Desenvolvimento da Educação Básica e estabelece metas para as escolas. Com isso, o objetivo deste artigo é analisar quais são as percepçóes dos professores das escolas públicas sobre a articulaçáo entre a Prova Brasil e a avaliação institucional. Por meio de entrevistas semiestruturadas e grupo focal em duas escolas, concluiu-se que há articulação entre a Prova Brasil e a avaliação institucional, promovida em diferentes reunióes presentes no ambiente escolar.
\end{abstract}

Palavras-chave: Prova Brasil. Avaliaçáo institucional. Qualidade do ensino fundamental.
Abstract

The municipal public schools of Campinas (SP) have a public policy of institutional evaluation, of democratic and emancipatory character; Concomitant to Prova Brasil, which gives rise to the Basic Education Development Index and sets goals for schools. Thus, the objective of this article is to analyze what are the perceptions of public school teachers about the articulation between Prova Brasil and institutional evaluation. Through semistructured interviews and focus group in two schools, it was concluded that there is articulation between Prova Brasil and the institutional evaluation, promoted in different meetings present in the school environment.

Keywords: Prova Brasil. Institutional assessment. Quality of elementary school.

1 Mestra em Educação pela Pontifícia Universidade Católica de Campinas. Lattes: http://lattes.cnpq. br/5673945459667624. Orcid: https://orcid.org/0000-0002-5824-1048. E-mail: carla_daniela_rc@ yahoo.com.br

2 Doutora em Educação pela Pontifícia Universidade Católica de São Paulo. Lattes: http://lattes.cnpq. br/8794565484100151. Orcid: https://orcid.org/0000-0002-8029-6395. E-mail: monica.rios@puccampinas.edu.br 


\section{Introdução}

Avaliar é uma prática que faz parte do cotidiano escolar, neste ambiente existem diferentes tipos de avaliaçôes, entre elas encontram-se as avaliaçóes de aprendizagem, elaboradas e aplicadas pelos professores, em períodos distintos do ano letivo para avaliar os avanços e dificuldades dos alunos e as avaliaçóes externas em larga escala, como a Prova Brasil, aplicadas a determinadas turmas ( $5^{\circ}$ e $9^{\circ}$ anos), a cada dois anos, nas escolas de todo o país, com o objetivo de aferir o ensino nesses níveis e formular açóes que visam à qualidade da educação básica. Além destas duas, há ainda no município de Campinas (SP), a Avaliação Institucional Participativa (AIP), que envolve todos os profissionais das escolas municipais de ensino fundamental e entre os seus objetivos estão avaliar a organização do trabalho pedagógico e seus impactos na aprendizagem e explicitar as diferentes responsabilidades de cada instância da Secretaria Municipal de Educação (SME) para ofertar uma educação de qualidade (SME, 2007).

A AIP é uma política pública, que foi implementada no município de Campinas (SP) em 2008, após uma parceria da SME e do Laboratório de Observação e Estudos Descritivos (LOED), da Faculdade de Educação da Universidade Estadual de Campinas (Unicamp). Desde então, as escolas municipais de ensino fundamental da rede constituíram as suas Comissóes Próprias de Avaliação (CPAs), visando obter o olhar de diferentes segmentos da comunidade escolar (pais, alunos, professores, funcionários e gestão) sobre as diversas questóes pertinentes ao ambiente escolar.

Considerando que "uma política pública é uma diretriz elaborada para enfrentar um problema público" (SECCHI, 2011) e que para o autor, a mesma possui dois elementos fundamentais: intencionalidade pública e a resposta a um problema público, compreende-se que a AIP surgiu em um contexto em que havia uma demanda a ser atendida pela SME.

Desse modo, analisar a percepçáo dos professores das escolas públicas municipais sobre essa política pública, em vigência há mais de dez anos nas escolas, se justifica à medida que houve à época um investimento do poder público para que a AIP se constituísse em um diferencial desta rede municipal. Percepçôes estas, que serão analisadas juntamente com a Prova Brasil, avaliação que compóem o Índice de Desenvolvimento da Educação Básica (Ideb), importante indicador da qualidade da educação.

Com isso, o objetivo desse artigo consiste em analisar quais são as percepções dos professores das escolas públicas municipais a respeito da articulaçáo entre a avaliação externa, no caso, a Prova Brasil, e a avaliação institucional 
desenvolvida na rede pública municipal de Campinas (SP). Objetivo esse, que denota o ineditismo do artigo, originado de uma pesquisa empírica.

Para tanto, foram pesquisadas duas escolas públicas municipais da cidade de Campinas (SP), uma com a maior e a outra com a menor média de Ideb, de 2007 a 2015, período considerado para a análise. A escola de maior média de Ideb será identificada como Escola I e a de menor média, será identificada como Escola II.

A produção do material empírico se deu por meio de entrevistas semiestruturadas e grupos focais com os professores dos $5^{\circ}$ anos e com a professora coordenadora da CPA. Ao todo, participaram da pesquisa sete professores, entre eles, quatro professores PEB II, dois professores que ministram aulas de educação física e uma professora coordenadora da CPA.

$\mathrm{Na}$ Escola I foram realizadas apenas entrevistas semiestruturadas e na Escola II, foi realizado um grupo focal com três professores e uma entrevista com a professora coordenadora da CPA.

Tanto a entrevista semiestruturada, quanto o grupo focal tiveram as seguintes questóes:

1- Qual a atuação da Comissão Própria de Avaliação (CPA) nessa escola? 2- Há articulação entre a avaliação externa, no caso a Prova Brasil e a avaliação institucional? Em caso afirmativo, como se dá essa articulação? 3- Qual a relação entre os resultados do Ideb dessa escola e os resultados da avaliação institucional? 4- Há espaços de problematização e discussão da avaliação institucional com a comunidade escolar? Em caso afirmativo, como se concretizam? 5- Há espaços de problematização e discussão da Prova Brasil e do Ideb com a comunidade escolar? Em caso afirmativo, como se concretizam?

A análise dos dados foi precedida pela transcrição das falas dos participantes da pesquisa, considerando, conforme Szymansky (2004, p. 74), que "a transcrição é a primeira versão escrita do texto da fala do entrevistado que deve ser registrada, tanto quanto possível, tal como ela se deu".

Em seguida, foi elaborado um quadro com as respostas na íntegra dos participantes acompanhadas da ideia central e das categorias que emergiram; por se compreender que "a categorização concretiza a imersão do pesquisador nos dados e a sua forma particular de agrupá-los segundo a sua compreensão" (SZYMANSKY, 2004, p. 75).

A partir das categorias elencadas, o processo de análise deu-se em um esforço de diálogo com os autores referenciados. A estrutura do artigo, além da introdução e da conclusão terá a caracterização das escolas pesquisadas, o perfil dos participantes da pesquisa e em seguida a análise das falas dos professores das duas escolas. 


\section{Caracterização das escolas}

A Escola I, com a maior média de Ideb, possui duas salas de $5^{\circ}$ ano, portanto, duas professoras PEB II e atende a alunos do $1^{\circ}$ ao $5^{\circ}$ ano do ensino fundamental, nos períodos da manhã e tarde, e os da Educação de Jovens e Adultos (EJA), no período noturno.

De acordo com o Projeto Pedagógico (PP) da escola, de 2019, o bairro em que se localiza é considerado central pela facilidade de acesso ao centro da cidade e às rodovias do entorno, com comércio variado e linhas de ônibus. É um bairro residencial de classe média baixa, com vários pontos comerciais, como farmácias, supermercados, lojas e restaurantes. Podem-se caracterizar as famílias atendidas pela escola como bastante heterogêneas social e economicamente, sendo a maioria dos alunos de famílias de classe média-baixa, havendo alguns alunos em situação de vulnerabilidade social e, por outro lado, outros com bom nível socioeconômico, transferidos de escolas privadas.

A Escola II, com a menor média de Ideb, possui uma docente que coordena a CPA e três salas de $5^{\circ}$ ano, com a mesma quantidade de docentes PEB II. Essa escola funciona nos períodos da manhã, tarde e noite e possui um maior número de discentes, por contemplar do $1^{\circ}$ ao $9^{\circ}$ ano do ensino fundamental e a EJA.

Consta no PP de 2017, que o bairro em que está localizada surgiu de uma ocupação, mas na atualidade, tem asfalto em várias ruas, casas de alvenaria substituindo antigas moradias de madeira e muitos comércios: mercados, farmácias, padarias, lojas de roupas, postos de saúde e lojas de bebidas. A comunidade é bastante diferenciada por ser uma antiga área de ocupação, os moradores são oriundos de diferentes regióes do país e apresentam uma diversidade cultural dificilmente encontrada em outra regiáo da própria cidade.

\section{Perfil dos participantes}

O perfil dos participantes pesquisados considerou o sexo (feminino - F; masculino - M), a idade, a formação (graduação, especialização, mestrado, doutorado), o tempo de atuação no magistério e o tempo de atuação na unidade escolar.

A fim de preservar as identidades dos participantes da pesquisa, no processo de análise, adotamos a letra $\mathrm{P}$ (professor), acompanhadas dos respectivos índices numéricos, especificando-se algarismo romano para identificação da escola e em seguida, algarismo arábico; especificamente para a professora coordenadora da CPA, foi utilizada a sigla CCPA. Em seguida, encontra-se um quadro com o perfil dos professores da Escola I. 
Quadro 1 - Perfil dos participantes da Escola I

\begin{tabular}{|c|c|c|c|c|c|}
\hline Participantes & Sexo & Idade & Formação & $\begin{array}{c}\text { Tempo de } \\
\text { atuação no } \\
\text { magistério }\end{array}$ & $\begin{array}{c}\text { Tempo de atuação } \\
\text { na unidade escolar }\end{array}$ \\
\hline PI1 & F & 45 & Especialização & 22 anos & 9 anos \\
\hline PI2 & F & 44 & Especialização & 17 anos & 15 anos \\
\hline PI3 & F & 28 & Especialização & 05 anos & 30 dias \\
\hline
\end{tabular}

Fonte: Dados da pesquisa.

Segundo o perfil das participantes da Escola I, as professoras PI1, PI2, exceto a PI3, possuem no mínimo nove anos de atuação na unidade escolar, sendo que a professora PI2 é a que a mais tempo está na escola, 15 anos. Todas as participantes possuem especialização, o que demostra que é um grupo que busca conhecimento e que valoriza a formação profissional. As participantes possuem em média mais de 15 anos de atuação no magistério, à exceção da PI3, podendo ser considerado assim, um grupo de professoras experientes.

Segue abaixo o quadro com o perfil dos participantes da Escola II.

Quadro 2 - Perfil dos participantes da Escola II

\begin{tabular}{|l|l|l|l|l|l|}
\hline Participantes & Sexo & Idade & Formação & $\begin{array}{l}\text { Tempo de } \\
\text { atuação no } \\
\text { magistério }\end{array}$ & $\begin{array}{l}\text { Tempo de atuação } \\
\text { na unidade escolar }\end{array}$ \\
\hline PII1 & F & 57 & Especialização & 20 anos & 8 anos \\
\hline PII2 & F & 45 & Especialização & 15 anos & 4 anos \\
\hline PII3 & M & 36 & Graduação & 9 anos & 2 meses \\
\hline CCPA & F & 55 & Especialização & 22 anos & 16 anos \\
\hline
\end{tabular}

Fonte: Dados da pesquisa. 
Ao realizar a análise do perfil da escola II, nota-se que exceto o PII3 que tem sua inserçáo recente na unidade escolar, o tempo mínimo de atuaçáo dos participantes da pesquisa é de quatro anos. Observa-se que a professora coordenadora da CPA (CCPA) é a que está há mais tempo na escola, 16 anos. Os participantes possuem em média 16 anos de atuação no magistério, o que indica uma equipe experiente e que também reconhece a importância da formação ao longo da trajetória profissional, sendo que três possuem especialização e apenas um possui apenas a graduação.

Especificamente no caso da professora CCPA e da PII1 que estão a mais tempo na escola e consequentemente na rede municipal, infere-se que tenham vivenciado a implementaçáo da AIP, o processo de adesão e a evoluçáo dessa política.

\section{As percepções das professoras da Escola I}

Ao serem instadas a refletir sobre a atuação da CPA na escola I, as participantes da pesquisa mencionaram com mais ênfase a realização de reunióes e os espaços para problematizaçáo do contexto escolar. A exceção se efetiva na fala de uma professora: "É, na minha visão, praticamente inoperante" (PI1).

Os membros sentam e sempre se reúnem e conversam sobre as açôes que existem nas escolas, as dificuldades, problemas, e tentam levar isso pra dentro da sala de aula, para os professores trabalharem com os alunos, e sempre na intençâo de tentar resolver essas dificuldades (PI3).

Destaca-se o potencial transformador da realidade, diante da problematização do contexto escolar gerada nos encontros mensais. Problematizar a realidade pode ser determinante para que a escola se converta em um espaço de aprendizagem e alegria, ingredientes fundamentais, quando se pensa a qualidade do ensino fundamental. Uma escola que abrigue um ambiente que assim se traduza encontra inspiração em Freire, ao poetizar o espaço escolar.

Lugar onde se faz amigos, [...] gente que trabalha, que estuda, que se alegra, se conhece, se estima. [...] e a escola será cada vez melhor na medida em que cada um se comporte como colega, amigo, irmáo. [...] nada de ser como o tijolo que forma a parede, indiferente, frio, só. [...] numa escola assim vai ser fácil estudar, trabalhar, crescer, fazer amigos, educar-se, ser feliz (FREIRE, s.d.).

Ao certo, essa escola poetizada por Freire necessita de um intenso trabalho coletivo e participativo que abarque as dimensóes da qualidade que encerram a infraestrutura, o planejamento e a gestão, a formação dos professores e as práticas pedagógicas. 
Essa concepção aponta para a valorização da participação dos diferentes atores com o reconhecimento de que a dimensão da qualidade que encerra aspectos relacionados à infraestrutura é mais perceptível para os atores que integram a $\mathrm{CPA}$, que os aspectos que se referem à dimensão que implica o pedagógico. $\mathrm{E}$ essa perspectiva não causa estranheza, posto que, de fato, a dimensão pedagógica constitui-se mais complexa, se consideramos os saberes que a permeiam. No entanto, a cultura de participaçáo tende a contribuir para a apropriação e progressiva ampliação do olhar sobre essa dimensão, para além de saberes acadêmicos, o que pode vir a favorecer a reflexão e problematização que lhe são atinentes, envolvendo os diferentes atores que integram a CPA.

Sobre a articulação entre a Prova Brasil e a avaliação institucional, somente a professora PI3 demonstrou desconhecimento a respeito. A participante PI1 afirmou não haver uma avaliação institucional própria na escola e, assim, também não identificou possível articulação, conforme questionado. A PI2 disse que a articulação se dá por meio da análise e discussão da Prova Brasil, em reunióes de Trabalho Docente Coletivo (TDC) e de CPAs.

A gente geralmente costuma fazer um TDC depois da avaliação da Prova Brasil, a gente costuma ver e analisar algumas questöes. [...] Em relação à Prova Brasil, a gente vê também algumas questôes, mas a gente faz uma análise mais geral do resultado do aproveitamento dos alunos (PI2).

No que se refere à relaçáo estabelecida entre os resultados do Ideb da escola e da avaliação institucional, as professoras PI1 e P12 náo expressaram possível relação. No entanto, a PI1 reconhece que no espaço escolar, o Ideb é comentado pontualmente, sobretudo, no que tange à melhora do índice, o que abarca o desempenho em Língua Portuguesa e em Matemática. A fala da professora PI1 expressa, ainda, que os comentários tecidos em reunião não implicam responsabilização. A participante PI2, por sua vez, identifica o Ideb como sendo reflexo do trabalho realizado, com vistas a uma educaçáo de qualidade, sendo o resultado do Ideb comentado em reunióes de TDC. Ainda que não ocorra segundo a PI1, uma problematização de fato sobre esse índice, o que poderia corroborar com açôes a serem discutidas e efetivadas, também não há responsabilização dos professores. Sobre essa condição, Freitas reitera que,

Os processos de responsabilização concorrenciais rompem a confiança relacional ao exporem indevidamente o desempenho de gestores, pais, professores e alunos: se os alunos aprendem, os professores são responsáveis; se não aprendem, os professores também são responsáveis; se os alunos não aprendem, os professores tendem a culpabilizar o próprio aluno ou os pais ou a falta de condiçóes de trabalho; os gestores livram-se de pressão superior rolando a culpa para baixo, em direção a professores, alunos e pais (FREITAS, 2014, p. 1099). 
A fala da participante PI3, na condição de professora expressa a crença de que o elevado Ideb da escola está relacionado à avaliação institucional.

Olha, acredito que, neste indice, a escola apresenta bons resultados, e acredito muito que tem a ver com esta avaliação, que é feita todo ano dentro da escola. Todos os professores, sempre no inicio e no final do ano, eles pegam aquilo que foi produtivo [...]. E ai, pegam os resultados destas provas, como a Prova Brasil, e tentam melhorar, trabalhar em cima dos temas que caem, discutir quais foram as dificuldades que os alunos apresentaram, para tentar ver, se no ano seguinte, consegue ser melhorado (PI3).

A fala da participante PI3, transcrita acima, indica que há discussão dos resultados da Prova Brasil, em reunióes (ainda que não especifique se de TDCs ou CPAs), nas quais os professores analisam os índices alcançados, com o intuito de verificar o que necessita ser melhorado.

O fato de ser reconhecida a relação entre os resultados do Ideb e os da avaliação institucional indica que não há, nesta escola pesquisada, o risco apontado por Almeida et al. (2013).

A utilizaçáo dos resultados das avaliaçóes em larga escala no Brasil tem se apresentado muito como sinônimo do trabalho desenvolvido pelas escolas, mas não se demonstra benéfica, tendo em vista que grande parte do desempenho não pode ser atribuída somente ao trabalho da/ na escola (ALMEIDA et al., 2013, p. 1168).

Nesse sentido, a avaliação institucional se mostra como uma proposta que privilegia a participação e entende que a responsabilidade pela qualidade da educação, não se restringe à escola.

O foco deste modelo é permitir a atuação governante daqueles sujeitos que são qualificados para este debate: a própria comunidade escolar. Nesta concepção, são estas pessoas que podem exercer influência decisiva e assertiva nos processos de qualificação das instituiçôes escolares (MORAES; PENTEADO, 2017, p. 112).

Em relação aos espaços de problematização e discussão da avaliação institucional com a comunidade escolar, a única entrevistada que apresentou uma resposta divergente em relação às demais foi a professora PI1, que disse não haver tais espaços na escola. Observa-se que tal fala apresenta coerência com a sua percepção sobre a atuação da CPA na referida escola, ao considerála inoperante. 
Não! Neste ponto, não. É no máximo, talvez, superficialmente, porque dai, a gente é obrigado a participar das reunióes de conselho, essa[s], junto com a comunidade [...] (PI1).

A PI3 destacou que as discussóes e problematizaçóes ocorrem, sobretudo, nas reuniōes de CPAs, nos Conselhos e nas reunióes de pais.

Sim, acredito que sim. Principalmente, nas Reunióes de Pais. Toda dificuldade da escola que a gente conversa nas Reunióes Pedagógicas de Avaliação Institucional (RPAIs) também é passada para a comunidade nas reunióes de pais. Também, nos Conselhos [...] (PI3).

Ainda que haja reconhecimento sobre a problematização da avaliação institucional com a comunidade escolar, ficou evidenciado que tal discussáo é tecida em diferentes espaços coletivos, a saber: reunião de pais, de CPAs e conselhos, parecendo não haver uma ocasiáo específica em que essas discussóes se deem. Por mais que uma parte da comunidade escolar esteja presente nas reunióes de pais, por exemplo, esse não pode ser considerado o momento mais adequado para esses assuntos, pois já possui as suas próprias demandas, assim como as reuniōes de Conselho.

A CPA, esta sim, por ter uma composição que abrange não somente pais e professores, mas alunos, equipe gestora e funcionários, constitui espaço propício para problematizar a avaliação institucional, articulando-a aos resultados do Ideb. Desse modo, é possível que todos os representantes da comunidade escolar contribuam para que se pense a escola para além do que esse índice representa, considerando que avalia apenas uma parte do trabalho escolar, não contemplando todos os demais esforços empreendidos para uma educação de qualidade. Sendo que,

Escolas que trabalham com a comunidade local portamse como centros irradiadores de lógicas avaliativas emancipatórias, as quais não se furtam ao controle social sobre os resultados dos processos que desenvolvem e que podem ser obtidos de forma mais integradora, aproveitando saberes e experiências, equivocadamente descartados pelas políticas educacionais mais preocupadas com os índices obtidos pelos estudantes nos exames nacionais ou internacionais, sem interrogar como estes são obtidos (MENDES et al., 2015, p. 1288).

Ainda que a professora PI2 admita que há esses espaços de discussão e problematização da avaliação institucional com a comunidade escolar, ela pontua que estes não são frequentes.

Sim, a gente faz isto com o Conselho de Escola, mas não é sempre [...] mas a parte pedagógica, mesmo, fica mais com o CPA. Não é sempre, mas tem (PI2). 
Essa fala aponta que a escola busca criar espaços de problematização e discussão da avaliaçáo institucional com a comunidade escolar, nas ocasióes em que os familiares dos alunos váo à unidade, nas reunióes de pais, de CPA e de conselho, momento que se torna oportuno, então, para os assuntos relacionados a essa avaliação.

Em relação à existência de espaços para a problematização e discussão da Prova Brasil e do Ideb com a comunidade escolar, as professoras PI1 e a PI2 não reconhecem a existência dos referidos espaços, conforme ilustram as falas que seguem.

Eu acredito que não. Que eu me lembre, não! No máximo, em um algum começo de reunião, ou começo de ano letivo, alguma coisa, dizendo que a escola ocupa tal colocação [...] (PII).

Não. Geralmente, não, que eu saiba. Pois pode ser que faltei em alguma reunião. Mas eu acho que não. A gente só fala os resultados para os pais, e a gente tem um painel, onde a gente deixa, também, um mural com os resultados do Ideb (PI2).

Contudo, na percepção da professora PI3 há existência de espaços destinados à problematização e discussão da Prova Brasil e do Ideb com a comunidade escolar, conforme evidencia a seguinte fala.

Durante as reunióes com os professores, sim, e eu já presenciei. O grupo, assim, da escola. Mas com os pais, eu acredito que, talvez, mais as reunióes de final de ano, depois que é passada essa prova. Eu acredito que é assim, desta maneira (PI3).

Em face de parte das participantes da pesquisa apontar a não existência de espaços de problematizaçáo e discussão da Prova Brasil e do Ideb com a comunidade escolar, e parte reconhecer a existência desses espaços, há necessidade de conferir visibilidade, a fim de que haja ciência da comunidade escolar como um todo, de modo a configurar um espaço democrático, considerando que "sem espaços formais que oportunizem encontros entre os atores, a experiência de participação esmorece, dificultando a construçáo de uma ambiência democrática" (SORDI; BERTAGNA; SILVA, 2016, p. 179).

De fato, as reunióes de CPA e de Conselho de Escola são os lugares onde estão presentes a comunidade escolar, além dos professores, gestores e funcionários da unidade. Momentos que devem ser aproveitados para se problematizarem diversas questóes inerentes ao ambiente escolar, inclusive, a Prova Brasil e o Ideb.

\section{As percepções dos professores da Escola II}

Nessa escola, foi realizado um grupo focal com três professores e uma entrevista semiestruturada com a professora coordenadora da CPA. Quando perguntados sobre qual a atuação da CPA na escola, apenas a professora PII1 não respondeu à questão, contudo, na sua fala, ficou expresso que a escolha dos 
membros dessa comissão é feita por votação, além de ressaltar o empenho dessas pessoas em participarem.

A professora PII2 e o professor PII3 responderam que a comissão é atuante e democrática na escola, conforme descrito a seguir.

A CPA nessa escola, nessa unidade, é bastante atuante, e como a M. disse, democrática, porque é feita através de eleição, eles participam ativamente (PII2).

Senti a questão democrática, das escolhas, e agora estou entendendo que é bastante influente e positiva (PII3).

Essas falas trazem algo que é essencial para a existência da CPA: a participação. Sem a comunidade escolar, ela não se sustenta. Trazer as famílias para as escolas é uma tarefa difícil, no entanto, necessária, destacada por Malavasi (2009): "Assim como em outros processos que se pretendem democráticos, é preciso que as famílias se sintam acolhidas pelas CPAs e que estas potencializem a presença e a participação das famílias" (MALAVASI, 2009, p. 185).

Do mesmo modo, a professora CCPA em sua resposta tratou do papel da CPA de avaliar a escola em seus aspectos físicos, pedagógicos, a qualidade dos processos de ensino, aprendizagem e a vivência escolar. A professora CCPA acrescentou, ainda, que essa comissáo promove o protagonismo dos alunos.

Ela atua no sentido de observar e estudar todos os aspectos físicos, pedagógicos relacionados ao ensino e aprendizagem, ou seja, tudo aquilo que está relacionado e que pode ajudar ou não o desenvolvimento do ensino pedagógico. [...]. A CPA também acolhe as crianças, faz com que elas se sintam protagonistas, elas säo parte integrante do processo educacional delas mesmas, elas se sentem responsáveis por isso [...] (CCPA)

Destaca-se a relevância da fala dos participantes, posto que a função de avaliar é inerente à CPA, pois surgiu para essa finalidade: avaliar a escola como um todo, porém, de modo coletivo, não de forma unilateral, como ocorre com as avaliaçóes externas.

A CPA é entendida não só como espaço de avaliação e implementação de mudanças, mas também como espaço de aprendizagem. Cada segmento, sob sua ótica, contribui para a construção de um trabalho coletivo, pois toma como base as especificidades, articulaçóes e experiências vivenciadas no âmbito de cada escola, visando à melhoria da qualidade social da educação da escola pública (SILVA; VIEIRA, 2012, p. 66).

A respeito da articulação entre a Prova Brasil e a avaliação institucional, o professor PII3 não detinha informação, devido a estar a pouco tempo na escola (3 meses) e a professora PII1 contemplou em sua fala a atuaçáo positiva dos dois orientadores pedagógicos quanto ao trabalho realizado com os professores. 
As professoras PII2 e a CCPA disseram haver articulação entre a Prova Brasil e a avaliação institucional em reunióes, entre elas, reunióes de pais, de CPAs e nas RPAIs. A professora CCPA acrescentou que a promoção dessa articulação é favorecida pela participação dos alunos em colegiados como a CPA.

Eu acho que dialoga um pouco, principalmente, nas RPAIS. Agora, dentro das CPAs, eu não vejo tanto essa relaçáo com a Prova Brasil. Mas de um modo geral, tudo está conectado, pois uma coisa depende da outra, obviamente (PII2).

Há [articulação]. Reflete diretamente. Tanto é que nós atingimos os indices do Ideb, ultrapassamos aquilo que estávamos esperando, precisamos crescer mais ainda. [...] Refletiu [tanto] no Ideb quanto nas outras avaliaçôes, diminuição da evasão escolar, faltas - ainda temos, mas é menos do que tínhamos -, participação dos órgãos da escola, Conselhos, Grêmios, CPA (CCPA).

Brandalise (2010, p. 319), considera que "a avaliação institucional da escola é produto da integração e entrelaçamento dos processos de avaliação externa e interna". Com isso, no processo da avaliação institucional, avaliaçóes como a Prova Brasil devem estar presentes nas discussóes ali tecidas, a fim de que se busque uma articulação, uma vez que, para a autora, "o processo de avaliação externa deverá completar-se com o processo de autoavaliação institucional, e vice-versa".

O desenvolvimento dessas ações demonstra o quanto a escola tem buscado essa articulação, o que também poderia explicar a elevação do seu Ideb nas últimas ediçóes da Prova Brasil.

Ao serem instados a refletir sobre a relação entre os resultados do Ideb da escola e da avaliação institucional, os professores PII1 e PII3 expressaram falas semelhantes à reflexão tecida sobre a articulação entre a Prova Brasil e a avaliação institucional, conforme análise apresentada.

A professora PII1 não respondeu à questáo, no entanto, a sua fala fez referência a um período em que a escola tinha um quadro incompleto de professores e gestores, resultando, consequentemente, em um Ideb baixo. E o professor PII3, devido ao pouco tempo de atuação na escola, não conseguiu contribuir.

As falas das professoras PII2 e da CCPA convergiram. Assim, nas duas respostas, observa-se que há relação entre os resultados do Ideb da escola e da avaliação institucional e que a solidificação da avaliação institucional melhora os índices.

Dialogam bastante. O Ideb, nessa escola, aumentou muito, de uma maneira muito bacana, e nós até comemoramos isso, porque era um Ideb baixissimo e deu salto grande, tanto no Ciclo I e II, quanto no III e IV [...] (PII2).

Existe [relação]. Na medida em que a avaliação institucional melhora, no que diz respeito ao vandalismo, a diminuição de faltas, alimentação, espaços escolares, ao material, então, melhoram também os indices (CCPA).

Diante disso, verifica-se que uma avaliação auxiliou a outra: não se excluíram, 
mas se complementaram. Ambas estão a serviço da efetivação de melhorias que influenciem nos processos de ensino e aprendizagem. Reafirmando, conforme Tomaz e Silva (2017), a importância da problematização do Ideb e não o seu abandono.

O fato é que não basta "medir" a qualidade da escola. Os dados de avaliação devem produzir sentidos, e estes se ampliam quando estão próximos dos atores da escola. Esquecidos nos relatórios, eles acabam inertes e desprezíveis, truncando-se as possibilidades de transformaçáo qualitativa da realidade das instituiçóes escolares (TOMAZ; SILVA, 2017, p. 150).

Em relação aos espaços de problematização e discussão da avaliação institucional com a comunidade escolar, todos os participantes disseram que na escola há estes momentos e houve participantes que salientaram a interação da escola com a comunidade escolar, o que demonstra um estilo de gestáo que propicia a participaçáo.

Então, a escola faz o possivel para poder se conectar com a comunidade [...] a escola, com o corpo docente e os gestores, a gente faz um trabalho muito "esforçante" para poder interagir com as pessoas da comunidade. Ejá está apresentando resultados, pois ano após ano, a gente está vendo os pais participando mais (PII1).

Eu tenho visto os pais mais presentes, aqui na escola, existem algumas mäes que são bem atuantes, inclusive, dentro da CPA. Elas participam juntos com seus filhos, $e$ isto é um motivo de grande alegria para nós e de ganho, porque esse diálogo entre a escola, a comunidade e os pais, é muito importante para uma escola (PII2).

Os demais participantes disseram que os espaços de problematização e discussão da avaliação institucional com a comunidade escolar ocorrem em reunióes, sejam elas de pais, sejam de CPAs, como destacam as falas a seguir.

Estou chegando agora, então, eu imagino que é nesse caminho, assim, mais uma reunião de Pais (PII3).

As reunióes da CPA têm a participação de pais, eles estáo na comunidade, eles participam, nos ajudam, acompanham as crianças e veem o comportamento deles [dos alunos] (CCPA).

As falas do professor PII3 e da professora CCPA demonstram haver reconhecimento sobre o esforço em trazer a comunidade para dentro da escola, sinalizado pelas reunióes de pais, que, neste caso, parece se constituir como uma das formas mais efetivas de participaçáo dos familiares. No entanto, segundo Malavasi et al. (2017),

Nos parece essencial que a participação das famílias possa se efetivar não apenas enquanto acompanhamento das atividades escolares e questões comportamentais de 
seus filhos, mas principalmente, na tomada de decisóes pedagógicas e na construção da qualidade socialmente referenciada (MALAVASI et al., 2017, p. 303)

É interessante notar que todos os participantes, mesmo os que não especificaram em que momentos se dá essa problematização, no caso, as professoras PII1 e PII2, tiveram respostas semelhantes, demonstrando que o trabalho que vem sendo realizado é reconhecido por todos, tornando-se, portanto, efetivo dentro da unidade escolar.

Para Sordi (2017, p. 309), "cabe às equipes gestoras exercer protagonismo e construir condiçóes para que a Avaliação Institucional Participativa (AIP) possa ser aprendida e experienciada pela comunidade escolar".

Questionados sobre se há espaços de problematização e discussão da Prova Brasil e do Ideb com a comunidade escolar, a professora coordenadora da CPA disse que são abertos esses espaços, em reunióes de pais, RPAIs e CPAs.

A gente faz isso durante as reunióes. Tem uma faixa aqui no pátio que foi colocada na escola e passada para os pais. A gente recebeu ONGs que vieram trabalhar com a gente. A comunidade também foi chamada para uma reuniáo, em todos os periodos, e contamos essa situação (CCPA).

A professora PII1 também respondeu que há esses espaços, no entanto, não os considera tão efetivos, como indica a sua fala.

Há espaço, mas essa questão ainda não é tão efetiva como o esperado, por causa da desmotivação da comunidade, na participação dos pais no movimento da escola. [...] mas há esse espaço sim, com certeza. É dado todo espaço possivel (PII1).

Ainda que se conceda esse espaço, diante da desmotivação da comunidade citada pela professora Malavasi (2009, p. 184), acrescenta que "a escola precisa criar planos de ação, levando em conta a realidade de seu entorno e as necessidades de sua comunidade para que esta se aproxime".

$\mathrm{Na}$ mesma direção, a professora PII2 reconhece a existência desses espaços de problematização e discussão da Prova Brasil e do Ideb com a comunidade escolar, mas enfatiza que há mais conscientização dos alunos do que dos pais e familiares.

[...] há esse espaço, mas ainda não estamos vendo essa participação sobre a Prova Brasil. Ainda não vejo. Os alunos, sim, estão muito mais conscientes, nós discutimos isso com eles. Mas [n]os pais e [n] a comunidade, ainda não vejo isso, estão engatinhando nesse processo (PII2).

Neste caso, observa-se que a escola, apesar de oferecer esse espaço por meio das reuniōes e exposição do seu Ideb em cartaz, parece ainda não atingir de modo específico os pais, talvez, por não estarem dentro da escola todos os dias, como os alunos, que em decorrência dessa vivência, como disse a própria professora, tenham mais consciência sobre o que é a Prova Brasil. 
O que também não significa que ocorra uma discussão ou problematização sobre o que esse índice diz a respeito da unidade escolar. Com isso, tornam-se importantes, ações que busquem articular a avaliação externa e a institucional, de modo que se reconheça o que trazem os dados gerados pela Prova Brasil e se pense no coletivo quais desdobramentos podem se dar a partir deles.

Ter a comunidade escolar envolvida nesse processo, por meio da avaliaçáo institucional, significa ouvir vozes distintas que contribuem para que se construa uma educação não voltada para a elevação de índices, mas sim, para o alcance da qualidade.

\section{Conclusões}

Este artigo, que teve como objetivo analisar quais são as percepçóes dos professores de duas escolas públicas municipais a respeito da articulação entre a avaliação externa, no caso, a Prova Brasil, e a avaliação institucional desenvolvida na rede municipal de educação de Campinas (SP), uma com a maior e a outra com a menor média de Ideb, possibilitou evidenciar que a Prova Brasil, em vigor desde 2005, se tornou uma importante avaliação que realiza um diagnóstico da educação brasileira e que auxilia a compor o Ideb, que vem se destacando como um indicador de qualidade das escolas. A despeito desse destaque, as escolas de ensino fundamental da referida rede pública municipal de educaçáo desenvolvem expressivo processo de avaliação institucional, desde 2008.

Perante este cenário em que a Prova Brasil não pode ser enxergada de modo isolado do contexto escolar, essa avaliação também não pode ser ignorada. É preciso que se discutam e problematizem os seus resultados na direção de como podem auxiliar o desencadeamento de açóes a serviço das aprendizagens e, no caso de Campinas (SP), de que modo os seus resultados podem ser articulados aos resultados da avaliação institucional.

O desafio para tal articulação, contudo, é notório e reside, sobretudo, nos propósitos e concepçóes distintos das referidas avaliaçóes. Por um lado, a avaliação em larga escala, no caso, a Prova Brasil, centrada no desempenho dos alunos, náo considera os fatores intra e extraescolares que afetam as aprendizagens dos alunos e que implicam o sucesso escolar. Por outro lado, a avaliaçáo institucional realizada pelas escolas da rede pública municipal de Campinas (SP) consiste em uma avaliaçáo de caráter participativo e democrático, que por meio da CPA, busca discutir a escola em suas potencialidades e fragilidades, propondo soluçóes que podem partir da própria unidade escolar ou acionar outras instâncias do poder público.

As expressóes dos participantes de ambas as escolas pesquisadas revelaram que há articulação entre os resultados da Prova Brasil e os da avaliação institucional, que ocorre principalmente por meio das reuniôes das CPAs, de pais e RPAIs. 
No entanto, em função do manifestado, essa articulação não é reconhecida por todos os professores participantes da pesquisa de ambas as escolas. Alijar professores, ainda que em número reduzido, desse processo, pode colocar em questão o caráter participativo da avaliação institucional.

Partindo do pressuposto, com base nos autores que balizam este estudo, de que a articulação dos resultados das referidas avaliaçóes tem potencial para contribuir com as aprendizagens dos alunos, é necessário que tal articulação seja intensificada e que sejam ampliados os espaços para esse fim, além de conferir visibilidade para toda a comunidade escolar.

\section{Referências}

ALMEIDA, L. C.; DALBEN, A.; FREITAS, L. C. O ideb: limites e ilusões de uma política educacional. Educ. Soc., Campinas, v. 34, n. 125, p. 1153-1174, out-dez. 2013.

BRANDALISE, M. Â. T. Avaliação Institucional da escola: conceitos, contextos e práticas. Olhar de Professor, Ponta Grossa, PR, v. 13, n. 2, p. 01-13, 2010

FREITAS, L. C. Os reformadores empresariais da educação e a disputa pelo controle do processo pedagógico na escola. Educ. Soc., Campinas, v. 35, no ${ }^{\circ}$ 129, p. 1085-1114, out.- dez., 2014.

INSTITUTO PAULO FREIRE. Disponível em: https://www.paulofreire.org/. Acesso em: 20 mai. 2019.

MALAVASI, M. M. S. Avaliação Institucional e gestão da escola: A participação das famílias potencializando uma educação de qualidade. In: SORDI, M. R. L. de; SOUZA, E. da S. (org.). A avaliaçáo como instância mediadora da qualidade da escola pública. A Rede Municipal de Educaçáo de Campinas como espaço de aprendizagem. Campinas (SP): SME/Campinas e Millennium Editora, 2009, pp. 171-187.

MALAVASI, M. M. S.; ALMEIDA, L. C.; FERRAROTTO, L.; RODRIGUES, J. D. Z.; CARRA TUSCHI, A. P. Participação como indicador de qualidade social: A visão das famílias sobre a escola. In: SORDI, M. R. L.; VARANI, A.; MENDES, G. do S. C. V. (Org.). Qualidade(s) da escola pública: reinventando a avaliação como resistência. Uberlândia: Navegando Publicaçóes, 2017, pp. 293-308.

MENDES, G. do S. C. V.; CARAMELO, J.; ARELARO, L. R. G.; TERRASÊCA, M.; SORDI, M. R. L. De; KRUPPA, S. M. P. Autoavaliação como estratégia de resistência à avaliação externa ranqueadora. Educ. Pesqui. São Paulo, v. 41, n. especial, p. 1283-1298, dez., 2015. 
MORAES, M. C. M. de; PENTEADO, T. C. Z. Um olhar para os avanços e recuos do processo de Avaliaçáo Institucional Participativa da rede municipal de Campinas. In: SORDI, M. R. L.; VARANI, A.; MENDES, G. do S. C. V. (Org.). Qualidade(s) da escola pública: reinventando a avaliação como resistência. Uberlândia: Navegando Publicaçôes, 2017, pp. 103-118.

SECCHI, L. Políticas Públicas: Conceitos, Esquemas de análise, Casos Práticos. São Paulo: Cengage Learning, 2011.

SECRETARIA MUNICIPAL DE EDUCAÇÃO. Plano de Avaliaçáo Institucional Participativa da Rede Municipal de Ensino de Campinas e FUMEC: uma alternativa para a educação básica de qualidade da Rede Municipal de ensino de Campinas e Fundação Municipal Para Educação Comunitária. Campinas (SP): SME/Campinas, 2007.

SILVA, J. de S.; VIEIRA, J. M. A. Estratégias de formação da política de AIP: Os encontros gerais das CPAs. In: SORDI, M. R. L. de; SOUZA, E. da S. (org.). $A$ avaliaçáo institucional como instância mediadora da qualidade da escola pública: o processo de implementação na rede municipal de Campinas em destaque. Prefeitura Municipal de Campinas, Secretaria Municipal de Campinas, 2012, pp. 65-82.

SORDI, M. R. L.; BERTAGNA, R. H.; SILVA, M. M. da. A Avaliaçáo Institucional Participativa e os espaços políticos de participação construídos, reinventados, conquistados na escola. Cad. Cedes, Campinas, v. 36, n. 99, p. 175-192, maio-ago., 2016.

SORDI, M. R. L. A força das palavras das equipes gestoras como recurso contra regulatório e os silêncios (in)compreensíveis na AIP. In: SORDI, M. R. L.; VARANI, A.; MENDES, G. do S. C. V. (Org.). Qualidade(s) da escola pública: reinventando a avaliação como resistência. Uberlândia: Navegando Publicaçóes, 2017, pp. 309-331.

SZYMANSKI, H. (org.). A entrevista na pesquisa em educação: a prática reflexiva. Brasília: Líber Livro, 2004.

TOMAZ, S. C.; SILVA, M. M. da. O que as escolas fazem que os testes estandardizados desprezam na avaliaçáo da qualidade? Ouvindo as escolas. In: SORDI, M. R. L.; VARANI, A.; MENDES, G. do S. C. V. (Org.). Qualidade(s) da escola pública: reinventando a avaliação como resistência. Uberlândia: Navegando Publicaçóes, 2017, pp. 143-167. 